Article

\title{
Toward Policies to Manage the Impacts of Autonomous Vehicles on the City: A Visioning Exercise
}

\author{
Luca Staricco*, Valentina Rappazzo ${ }^{\circledR}$, Jacopo Scudellari and Elisabetta Vitale Brovarone ${ }^{(\mathbb{}}$ \\ Interuniversity Department of Regional and Urban Studies and Planning, Politecnico di Torino, Viale Mattioli 39, \\ 10125 Torino, Italy; valentina.rappazzo@gmail.com (V.R.); jacopo.scudellari@polito.it (J.S.); \\ elisabetta.vitale@polito.it (E.V.B.) \\ * Correspondence: luca.staricco@polito.it; Tel.: +39-0110907441
}

Received: 8 August 2019; Accepted: 18 September 2019; Published: 24 September 2019

check for updates

\begin{abstract}
There is great uncertainty about the transition from human to autonomous driving vehicles (AVs), as well as about the extent and direction of their potential impacts on the urban built environment. Planners are aware of the importance of leading this transition but are hesitant about how to proceed, and public administrations generally show a passive attitude. One of the reasons is the difficulty of defining long-term visions and identifying transition paths to achieve the desired future. The literature on $\mathrm{AVs}$ is growing rapidly but most of the visions proposed so far do not consider in detail how circulation and parking of AVs will (or could) be differently regulated in cities. In this study, three visions for the Italian city of Turin are proposed. The aim of these visions is to highlight how different forms of regulation of $\mathrm{AV}$ circulation and parking can impact on the sustainability and livability of the city. A focus group and a set of interviews with experts and stakeholders were used to validate the three visions and assess their advisability and sustainability. This visioning exercise is the first step in the development of a backcasting process.
\end{abstract}

Keywords: autonomous vehicles; driverless; visioning; governance; regulation; circulation; parking — urban planning; urban design; uncertainty

\section{Introduction}

The transition to automated driving is underway [1-4], and the enthusiasm of media and manufacturers for this innovation is increasing. Scientific literature on this subject is also rapidly growing - the number of articles per year being more than doubled in the last five years. However, there is a great uncertainty about the time horizon of this socio-technical transition, as well as about the impacts that autonomous vehicles (hereinafter, AVs) will generate on our cities and lives.

According to Gartner's Hype Cycles, which give an overview of the relative maturity of technologies in a certain sector [5], AVs reached their peak of inflated expectations in 2015 and in recent years they have been moving towards a phase of disillusionment [6]. After a first period of enthusiastic optimism, a growing number of scholars have pointed out the possible negative impacts of AVs, in terms of car dependency, decline of public transport, inactivity, sprawl, etc. Recent comprehensive reviews of possible impacts of AVs are described in [7-10].

In this regard, the introduction of AVs could conflict with the objectives of sustainability and livability of many urban policies, if it is unconditionally left in the hands of technology enthusiasts and car manufacturers. This issue has raised concern in the scientific community, which deplores the widespread "watch and wait" approach by planners and public administrations, and calls for a better commitment $[7,11-13]$. However, while awareness of the importance of steering the introduction of $\mathrm{AVs}$ is rising, how to deal with such an uncertain future remains unclear. 
Backcasting is acknowledged as a suitable method for dealing with high degrees of uncertainty [14-17]. Unlike forecasting, which outlines future development scenarios based on current trends, backcasting moves in the opposite direction-it formulates future visions and goes backwards to define the actions needed to achieve them.

Several visions and scenarios with different focus and methodologies have been proposed for the circulation of AVs in the future [18-26]. However, visions and scenarios for AVs are often acontextual, as they do not refer to real cases and spaces in which these vehicles will be circulating and parking. The aim of this study was to propose a set of visions to explore how circulation and parking of AVs can be regulated to govern their impacts on different parts of the city, and to predict which opportunities and critical issues will emerge with respect to the sustainability and livability of the city. These visions are referred to as fully autonomous vehicles (SAE level 5), i.e., vehicles which are capable of operating on public roads (without the need for user supervision), regardless of the origin and destination of the trip or intervening road, traffic, and weather conditions.

Section 2 briefly reviews the possible impacts of AVs on the city as they emerge from the literature and highlights the importance of steering the introduction of AVs with proactive policies. Section 3 presents issues and methods for dealing with the uncertainty of this transition. Section 4 presents three visions of AV circulation and parking for the Italian city of Turin. These visions were discussed in a focus group with local experts and through a number of in-depth expert interviews-the results and insights are discussed in Section 5. Finally, Section 6 presents some concluding remarks on the implications of these results for urban policies.

\section{The Impacts of AVs on the City and the Role of Policies}

A wide range of potential impacts of the diffusion of AVs has been analyzed in the scientific literature $[27,28]$. Some of these impacts, which depend on the level of technology adopted and the rate of $\mathrm{AV}$ penetration in the mobility system, relate to the urban dimension in terms of form and structure of the city, as well as land use and consumption [29].

First of all, automated driving could radically reduce the road space needed for car circulation and parking [22,30,31], as AVs will be able to reduce the distance between vehicles and to pick up/drop off the riders door-to-door and then reach a parking lot. Roadside parking spaces could be removed (although at least partially replaced with dedicated spaces for picking up/dropping off) and transferred to multilevel parking facilities [9]. These facilities could be located outside the city where land is cheaper, freeing up space in the denser parts $[4,8]$.

At the same time, these benefits could be limited to the short term, and turn into negative impacts in the long term [12,32]. AVs could increase vehicle miles travelled [11,30,33], for several reasons. First, they could reduce the value of travel time, as passengers will not have to drive and could use travel time for other activities. This could foster sprawling processes, increasing average travel distances [4,21,34-36]. Second, AVs will allow car-less citizens (such as elderly, disabled, young people) to ride a car, improving their accessibility but also leading to extreme dependence on the car [22,37]. Finally, automated driving could increase the effectiveness of cars to the detriment of public transport and non-motorized mobility. In particular, active mobility could be adversely affected, with negative consequences for health; conflicts between $\mathrm{AVs}$ and pedestrians and cyclists could also arise [38-40].

Not only the magnitude, but also the (positive or negative) direction of most of these impacts is likely to depend on the extent of a shared use of AVs. Some research studies consider the possibility that a significant part of the current fleet of privately-owned cars could be replaced in the long term by shared vehicles, consequently increasing the positive effects of $\mathrm{AVs}$ or at least reducing their negative impacts [9,31,41,42]. For example, the International Transport Forum (2015) [43] suggested that only $10 \%$ of the current car fleet will be needed in the future, if all these cars are autonomous and shared, and are combined with a high-capacity public transport.

Urban and transport planning can play a key role in the transition to automated driving, as they can influence the direction of the above-mentioned potential impacts [44,45]. At the same time, given 
the uncertainty about the timing and the scale of these impacts, policymaking for AVs at the local and metropolitan level is quite complex, and defining pathways and making policy choices in such an uncertain context poses a number of challenges [3].

As recent surveys in the USA [11], Australia [12], and Germany [9] show, planners are often well aware of the technological progress and potential impacts of AVs, but are not sure how to deal with their diffusion in the planning choices. For example, it is acknowledged that today's decisions to invest in new railway and underground lines or motorways will modify the supply of local transport for decades, but over this same period AVs could substantially change the underlying nature of the mobility demand [46]. In this regard, Guerra [11] provides three basic suggestions about planning for AVs at the metropolitan level-(a) planners should not expect AVs to solve problems like congestion, traffic fatalities, or pollution on their own; (b) planners should promote investments and policies that make sense in a variety of future scenarios; and (c) planners should focus on policies that make sense today, regardless of the future of automation.

Some authors have provided policy recommendations to local governments in terms of transport and land use policies that cities and regions could implement in the short-to-medium term to progressively accommodate AVs in their local environments (see, for example, $[7,15,22,46])$. Most of these policies can be considered as "no regret" policies. Indeed, they contribute to increasing the sustainability of current mobility systems and, at the same time, their short- and medium-term effects could be useful to prevent negative AV impacts in the long term. Examples of these recommendations are-(a) promoting a high-quality multimodal transport system, in which AVs will be integrated but public transport will retain a major role in the transport offer; (b) enhancing electric mobility, to reduce the environmental impacts of human-driven cars now and that of AVs in the future; (c) encouraging the use of sharing services and MaaS practices over private motorized mobility, favoring a transition to shared AVs rather than to privately-owned AVs; (d) improving urban quality and design, to facilitate pedestrian and cycling mobility; (e) progressively reducing minimum parking requirements (as AVs will need fewer parking spaces) and devoting the freed up space to active mobility; (f) restricting access to cars inside and outside the city, and supporting the emergence of car-free neighborhoods; and (g) adopting regulations to prevent further sprawling processes.

In some respects, these recommendations are rather general. Visioning and backcasting can offer useful insights for implementing them in a specific local context.

\section{Visioning and Backcasting}

Planning is intrinsically linked to dealing with the future. It aims not only to predict it but also to steer development towards a desired goal [47]. Since the future is uncertain, uncertainty is a natural element of planning, both in terms of outcomes and the evolution of the object being planned. However, uncertainty might also be seen as an opportunity for planners and policy makers rather than a complication. This depends to a large extent on the attitude towards uncertainty-policymaking might be in line with the current or expected trends, or conversely might question them and envisage alternative futures to be pursued [48].

Walker et al. [49] proposed four levels of uncertainty-"a clear enough future"; "alternative futures (with probabilities)"; "a multiplicity of plausible futures"; and "unknown future". The third and fourth levels are referred to as "deep uncertainty", and mobility will undoubtedly go through a period of such levels of uncertainty [3,48,49], especially with regard to AVs.

There are several techniques that can help decision-makers face the future by setting scenarios. Among these techniques, backcasting is acknowledged as an appropriate method to address deep uncertainty $[14,16,17]$. While forecasting investigates probable and possible futures, backcasting goes in the opposite direction, from the future to the present. It identifies desirable futures and goals, and then defines policy paths to achieve them. According to Banister and Hickman's classification [14], a combination of backcasting and exploratory methods is perhaps the most convenient approach to building visions and scenarios on transport and mobility. In essence, this combination might consist 
of a multiple-vision backcasting approach that entails the normative nature of backcasting (often single-vision) and the flexibility of exploratory approaches.

Backcasting is normally structured in three phases [50] — visioning, in which business as usual and alternative visions of desirable transport futures are established; policy packaging, which elaborates a set of policy measures and pathways to steer development towards the desired outcome; and evaluation, through which the impacts of the identified policy paths are assessed against a set of criteria (environmental, social and economic impacts, as well as feasibility and acceptability, etc.). Envisioning the scenarios that will be subject to policy packaging and appraisal is, therefore, a crucial step. Although in the field of transport policy, scenario building and backcasting are commonly seen as expert-led activities, claims for stakeholder involvement from the beginning of their elaboration process (and in particular in the first visioning phase) are emerging in the debate $[16,44,50]$.

Several authors elaborated visions and scenarios for AV development, with different focuses and methodologies, and the literature on visioning for AVs is growing rapidly (for a recent review of scenarios, see Stead and Vaddadi [24]). Some visions are more focused on the socio-technical transitions [19], others on the expected implications of AVs [22], on friendliness of user types [23], on the combination of technological innovation and policy support aspects [21]. With regards to the time horizon, some visions refer to a period when most or all vehicles will be fully autonomous (20 to 30 years) $[18,20,22,23,25]$, while others also refer to the transition phase $[19,21,26]$.

Although each of them has a specific focus, the authors who have developed visions for AV transition are aware of the complex system of issues and variables at stake. Each scenario is grounded on a set of elements, players, goals, and development trends, which differ from one to another and depicts the complexity, uncertainty, and variety of perspectives. Yet, nearly all of these visions do not refer to the space in which AVs will be circulating and parking. Parkin et al. [39] propose four visions on the different patterns of AV circulation in the city (segregated network for AVs, AVs only on the main network mixed with human-driven cars, urban network, and shared space); nevertheless, even in this case space is mainly considered as a container, and the focus is on the interaction of AVs with other users.

\section{A Visioning Exercise}

This article presents an exercise aimed at prefiguring future AV visions for the Italian city of Turin. These visions explore how circulation and parking of AVs could be differently regulated in different parts of the city, and how mobility could be consequently and consistently re-organized. This section presents the aims and methods (Section 4.1), the case study (Section 4.2), and the three spatial visions (Section 4.3).

\subsection{Aims and Methods}

The purpose of this exercise is twofold:

- To analyse different forms of regulation of AV circulation and parking that can be implemented in a real city context, taking into account the structure of its road network, its neighborhoods, etc.

- To identify which of these forms can be considered the most advisable because of its sustainability; this can be used in a future backcasting exercise to identify which policies could be implemented in the short and medium term, in order to achieve it.

The methodological approach mixed two main methods for designing future normative visions-the think-tank model and the participatory model [51-53]. In the think-tank model, visions are generated back-office by a multidisciplinary research team, sometimes supported by external experts. In the participatory approach, a larger number of (expert and non-expert) stakeholders are involved in developing the visions. 
The visioning exercise entailed three different phases—development of three visions, validation of these three visions, and selection of the most advisable vision. The first two steps were based on the think-tank model, the third on the participatory model.

First, a brainstorming exercise was carried out by the research team to define possible future visions, all referring to a long-term time horizon (2050) in which all circulating vehicles is expected to be fully connected, autonomous (SAE level 5), and electric. This phase was grounded on a previous systematic review of the scientific and grey literature about the expected impacts of AVs on cities. The research team consisted of four urban and transport planners, a transport engineer, and a sociologist. The team identified fourteen items (described in detail in Section 4.3) that could be considered as key elements to regulate $\mathrm{AV}$ circulation and parking (such as road hierarchy, limitation to vehicle circulation, etc.), as well as to provide other modes of transport and mobility (lanes for public transport, cycling facilities, pedestrian areas, etc.). These fourteen items were differently developed and combined by the researchers for the case of Turin, according to a couple of scenarios that are frequently conjectured in the literature [22]:

- An optimistic and technology-centered scenario, which assumes that the impacts of AVs on the city (described in Section 2) will be largely positive. A "Strong deregulation" vision was developed under this scenario-in this vision, the fourteen items were devised assuming that AVs could solve most of the current transport problems in Turin.

- A pessimistic scenario, which presumes that the negative impacts of AVs on the city will prevail, if not properly managed. A "Strong regulation" vision was elaborated for Turin, by implementing the fourteen items according to the general policy recommendations described in Section 2.

- A further "Business as Usual" vision was proposed. This vision corresponds to a scenario in which the diffusion of AVs will not be explicitly governed, nor their positive or negative impacts. In this vision, the fourteen items are developed in a sort of inertial prolongation of the current planning conditions of the mobility system in Turin.

In a second phase, seven local experts and professionals in the transport sector, ranging from politicians to managers and technicians, were invited to discuss and validate these three visions in a focus group (the recommended number of participants to focus groups is generally 6 to 8 ; see for example Wilkinson [54]). Since the visions are focused on the regulation of AV circulation and parking, the experts were selected so as to represent the main institutions and companies which are in charge of transport planning, managing, and operating in the area of Turin:

- The Transport Department of the City of Turin.

- The Land Use and Transport Department of the Metropolitan Area of Turin.

- AMP_Agenzia della Mobilità Piemontese, the public transport Authority of Piedmont (the Italian region in which Turin is located).

- 5T-Tecnologie Telematiche Trasporti Traffico Torino, a public company providing info-mobility and Intelligent Transport Systems for the whole Piedmont region.

- GTT-Gruppo Torinese Trasporti, the main public transport company operating in Piedmont region.

- Blue Torino, a fully electric car-sharing provider operating in Turin since October 2016.

- Bike Pride, a local association focused on sustainable (in particular non-motorized) mobility.

The focus group lasted two and a half hours. It was moderated by two members of the research team, while three other members recorded the vital points of the discussion. First, the two moderators illustrated in detail the fourteen items of the three visions. The participants were then invited to debate each item, in order to confirm it, as proposed by the research team or to suggest how (and why) to develop it differently. The recorded results of this discussion were finally analyzed by the research team to definitively validate the three visions as proposed in the first phase, or modify them according to the suggestions of the participants in the focus group. 
In the third phase, the seven experts who participated in the focus group and the other 44 local stakeholders were interviewed to identify the most advisable of the three validated visions. They were asked to fill in a questionnaire to assess the "advisability" of each vision. In detail, in the questionnaire (previously tested using three respondents not included in the sample) they were requested to evaluate the advisability of each of the fourteen items of each vision on a scale from 1 ("absolutely not advisable") to 10 ("absolutely advisable"). An even scale was preferred in order to avoid a neutral point, forcing the respondents to take a position with regards the different items. Respondents were then invited to explain the reasons for their assessments and to argue about the need to govern (or not) the transition to AVs. The interviewed stakeholders were chosen so as to cover a wide range of actors interested in the possible (positive or negative) impacts of AVs on the city. They belonged to automotive companies involved in the production and sale of cars to providers of ICT and mobility services, research centers, public administrations, and environmentalist or professional associations (Table 1). Almost half of them were directly engaged in the pilot project for testing AVs that is now underway in Turin (see Section 4.2).

Table 1. The 51 interviewed stakeholders.

\begin{tabular}{cc}
\hline Sector & Category ( ${ }^{\circ}$ Interviews) \\
\hline Mobility and ICT services & 7 experts \\
\hline Public institutions and associations & Public transport (1), sharing (1), smart Mobility (1) \\
\hline Automotive & $\begin{array}{c}\text { Public administration (3), environmentalist } \\
\text { association (1) }\end{array}$ \\
\hline Mobility and ICT services & 44 stakeholders \\
\hline Research & $\begin{array}{c}\text { Automotive components (4), car production (5), } \\
\text { financing (1), insurance (1), testing (2) }\end{array}$ \\
\hline Public institutions and associations & $\begin{array}{c}\text { Public transport (4), sharing (2), smart mobility (7), } \\
\text { software (1), telecommunication (1) }\end{array}$ \\
\hline & $\begin{array}{c}\text { Consulting (1), innovation hub (2), real estate (1), } \\
\text { research center (2), university (1) }\end{array}$ \\
\hline & $\begin{array}{c}\text { Consumer association (1), environmentalist } \\
\text { association (2), public administration (3), professional } \\
\text { association (2), trade union (1) }\end{array}$ \\
\hline
\end{tabular}

In all three phases, the general framework assumed for defining, validating, and assessing the three visions was that of sustainability in its three dimensions (economy, society, and environment), referring to the most cited core values for the city of tomorrow, as reviewed by González-González et al. [15].

\subsection{Case Study}

The city of Turin was chosen as a case study. It is the fourth most populated Italian city (about 886,000 inhabitants in the city, 2.3 million in the NUTS-3 province); it is located in the north-western part of the country. Turin is largely car-dependent-it has one of the highest car ownership rates in Europe (639 cars/1000 inhabitants), and the modal share of private motorized mobility is quite significant (39\%) (source-EMTA Barometer 2015, Istat). Car circulation is poorly moderated; there is only one restricted traffic zone, covering $2 \%$ of the municipal areas, and few small $30 \mathrm{~km} / \mathrm{h}$ zones are active. Public transport (one metro, 8 streetcars, and about 90 bus lines) and the cycle network (nearly $200 \mathrm{~km}$ of cycle lanes and paths) are underused; their respective modal shares are $24.3 \%$ and $3 \%$. Hence, the prospective negative impacts of AVs can be particularly significant in this city if the transition is not governed. 
In 2018, the Municipality launched a pilot project for testing AVs. They will initially be tested in a closed, simulated urban area, and at a later stage on a 35- $\mathrm{km}$ route along the real road network. This real-world environment test aims primarily at placing Turin at the forefront of the transition to AVs in relation to its economic specialization in the automotive and ICT sectors.

The Sustainable Urban Mobility Plan (hereinafter, SUMP), adopted by the city in 2010, is now coming to the end of its 10-year validity period, and the elaboration of the next plan is underway. Therefore, this is the right time for the city to assess if short- and medium-term measures could be integrated into the new SUMP to try to steer the transition to AVs, and to assess which measures could be used.

\subsection{The Three Spatial Visions}

As anticipated in Section 4.1, the three visions were defined by the research team with reference to fourteen items, namely (Table 2):

1. Road hierarchy, based on articulation into main roads (1.1) and local roads (1.2).

2. Limitation to vehicle circulation.

3. Parking areas, with specific focus on roadside parking and areas to pick-up/drop-off the passengers (3.1), multilevel parking (3.2), and intermodal parking (3.3).

4. Local public transport, with specific focuses on main lines (4.1), feeder capillary network (4.2) and reserved lanes (4.3).

5. Shared mobility, differentiated between motorized (5.1) and non-motorized services (bike-sharing, $5.2)$.

6. Pedestrian areas.

7. Bicycle facilities.

8. Modal split.

Vision 1, called "Business as Usual" (BAU), is typified as a sort of inertial interpolation of the present conditions of the mobility system in Turin. It was conceived as the result of the implementation (in the following decades) of a set of policies that were in line with the ones set by the current SUMP. These policies are aimed at encouraging active mobility and the use of public transport and moderately deterring the use of private cars, but they are not tailored to assist and regulate the transition from human to autonomous driving. Therefore, the conversion could be expected to occur in a rather inertial way. In this vision, road hierarchy would be based on the distinction between main roads (Figure 1), whose speed limits would be set at $50 \mathrm{~km} / \mathrm{h}$, and local roads that have a speed limit of $30 \mathrm{~km} / \mathrm{h}$. Vehicle circulation would be banned in few restricted traffic zones. Parking spaces would be partly maintained on roads and partly concentrated in new intermodal and multilevel parking facilities (Figure 2); the freed-up road space would be allocated to AV circulation and ad hoc platforms to facilitate AVs' passengers getting on and off the vehicles. The public transport supply would be organized in main lines (running on reserved lanes) and a feeder capillary network. Several service providers will offer both motorized and non-motorized sharing services. Each neighborhood would have a pedestrian area (not very wide), both for the sake of road safety and to preserve the most valuable historical and artistic parts of the city. The bicycle network would consist of ten radial and four circular paths (corresponding to the vision of the current Bike Plan, adopted by the city in 2013). In the modal split of this vision, the use of private and shared motorized transport and of the bike would increase, as compared to the current situation; the use of public transport will decrease slightly; while pedestrian mobility would decrease substantially as a consequence of the use of AVs for door-to-door trips. 
Table 2. Summary description of the three visions.

\begin{tabular}{|c|c|c|c|}
\hline Item & $\begin{array}{c}\text { Vision } 1 \text { (Business as } \\
\text { Usual) }\end{array}$ & $\begin{array}{l}\text { Vision } 2 \text { (Strong } \\
\text { Deregulation) }\end{array}$ & $\begin{array}{l}\text { Vision } 3 \text { (Strong } \\
\text { Regulation) }\end{array}$ \\
\hline 1.1 Road hierarchy: Main roads & Speed limits: $50 \mathrm{~km} / \mathrm{h}$ & No speed limits & $\begin{array}{l}\text { Reserved to cut-through } \\
\text { traffic. Speed limits: } 50 \\
\mathrm{~km} / \mathrm{h}\end{array}$ \\
\hline 1.2 Road hierarchy: Local roads & Speed limits: $30 \mathrm{~km} / \mathrm{h}$ & No speed limits & $\begin{array}{l}\text { Reserved to access traffic. } \\
\text { Speed limits: } 20 \mathrm{~km} / \mathrm{h}\end{array}$ \\
\hline $\begin{array}{l}\text { 2. Limitations to vehicle } \\
\text { circulation }\end{array}$ & $\begin{array}{l}\text { Few restricted traffic } \\
\text { zones }\end{array}$ & $\begin{array}{l}\text { No limitations, except for } \\
\text { few pedestrian areas }\end{array}$ & $\begin{array}{l}\text { Every mesh of the main } \\
\text { road network is a home } \\
\text { zone, where circulation } \\
\text { is limited to shared AVs } \\
\text { and residents' AVs }\end{array}$ \\
\hline $\begin{array}{l}\text { 3.1 On-road parking; pick up/drop } \\
\text { off areas }\end{array}$ & $\begin{array}{l}\text { On-road car parks } \\
\text { partially removed; space } \\
\text { freed up for AV } \\
\text { circulation and pick } \\
\text { up/drop off areas }\end{array}$ & $\begin{array}{l}\text { On-road car parks totally } \\
\text { removed; space freed up } \\
\text { for AV circulation and } \\
\text { pick up/drop off areas }\end{array}$ & $\begin{array}{l}\text { On-road car parks totally } \\
\text { removed; space freed up } \\
\text { for non-motorized } \\
\text { mobility and pick } \\
\text { up/drop off areas }\end{array}$ \\
\hline 3.2 Multi-story parking & $\begin{array}{l}\text { Few new parking areas } \\
\text { in addition to the } \\
\text { existing ones }\end{array}$ & $\begin{array}{l}\text { Homogeneously } \\
\text { distributed in some areas } \\
\text { along the road network }\end{array}$ & $\begin{array}{l}\text { Distributed in some } \\
\text { areas along the border of } \\
\text { each home zone. }\end{array}$ \\
\hline 3.3 Intermodal parking & $\begin{array}{l}\text { Few new parking areas } \\
\text { in addition to the } \\
\text { existing ones }\end{array}$ & $\begin{array}{l}\text { Located at the termini of } \\
\text { the few maintained } \\
\text { public transport lines }\end{array}$ & $\begin{array}{l}\text { Located at the termini of } \\
\text { the main public } \\
\text { transport lines }\end{array}$ \\
\hline $\begin{array}{l}4.1 \text { Main public transport lines } \\
\text { (trains, metro, streetcars) }\end{array}$ & $\begin{array}{l}\text { Enhanced compared to } \\
\text { the current level }\end{array}$ & $\begin{array}{l}\text { Only trains and metro } \\
\text { are maintained; } \\
\text { streetcars lines are } \\
\text { removed }\end{array}$ & $\begin{array}{l}\text { Trains and metro are } \\
\text { enhanced; streetcars } \\
\text { lines on each main road }\end{array}$ \\
\hline $\begin{array}{l}4.2 \text { Feeder capillary network } \\
\text { (buses) }\end{array}$ & $\begin{array}{l}\text { Enhanced compared to } \\
\text { the current level }\end{array}$ & Totally removed & $\begin{array}{l}\text { Removed in home zones } \\
\text { and replaced by car } \\
\text { sharing or automated } \\
\text { shuttles }\end{array}$ \\
\hline $\begin{array}{l}4.3 \text { Lanes reserved to public } \\
\text { transport }\end{array}$ & $\begin{array}{l}\text { Enhanced compared to } \\
\text { the current level }\end{array}$ & Totally removed & Present on all main roads \\
\hline 5.1 Motorized AV sharing & Discrete supply & Strong supply & Strong supply \\
\hline $\begin{array}{l}5.2 \text { Non-motorized AV sharing } \\
\text { (bike sharing) }\end{array}$ & Discrete supply & Poor supply & Strong supply \\
\hline 6. Pedestrian areas & $\begin{array}{l}\text { Few new areas in } \\
\text { addition to the existing } \\
\text { ones }\end{array}$ & $\begin{array}{l}\text { Maintained only in the } \\
\text { historical city center }\end{array}$ & $\begin{array}{l}\text { All local roads in home } \\
\text { zones are shared spaces }\end{array}$ \\
\hline 7. Cycling facilities & $\begin{array}{l}\text { Ten radial and four } \\
\text { circular cycle paths }\end{array}$ & Totally removed & $\begin{array}{l}\text { Present on each main } \\
\text { road; free circulation } \\
\text { inside the home zones }\end{array}$ \\
\hline \multicolumn{4}{|l|}{ 8. Modal split } \\
\hline $\begin{array}{l}\text { pAV: Privately owned AVs } \\
\text { sAV: Shared owned AVs } \\
\text { PT: Public transport } \\
\text { C: Cycling } \\
\text { P: Pedestrians } \\
\text { - indicates moderate decrease } \\
\text { = indicates no change } \\
\text { + indicates moderate increase } \\
\text { ++ indicates strong increase }\end{array}$ & $\begin{array}{l}\text { pAV: }+ \\
\text { sAV: }+ \\
\text { PT: }=/- \\
\text { C: }+ \\
\text { P: }-\end{array}$ & $\begin{array}{l}\text { pAV: }++ \\
\text { sAV: }+ \\
\text { PT: }- \\
\text { C: }- \\
\text { P: - }\end{array}$ & $\begin{array}{l}\text { pAV: }- \\
\text { sAV: }++ \\
\text { PT: }=/+ \\
\text { C: }=/+ \\
\text { P: }+\end{array}$ \\
\hline
\end{tabular}




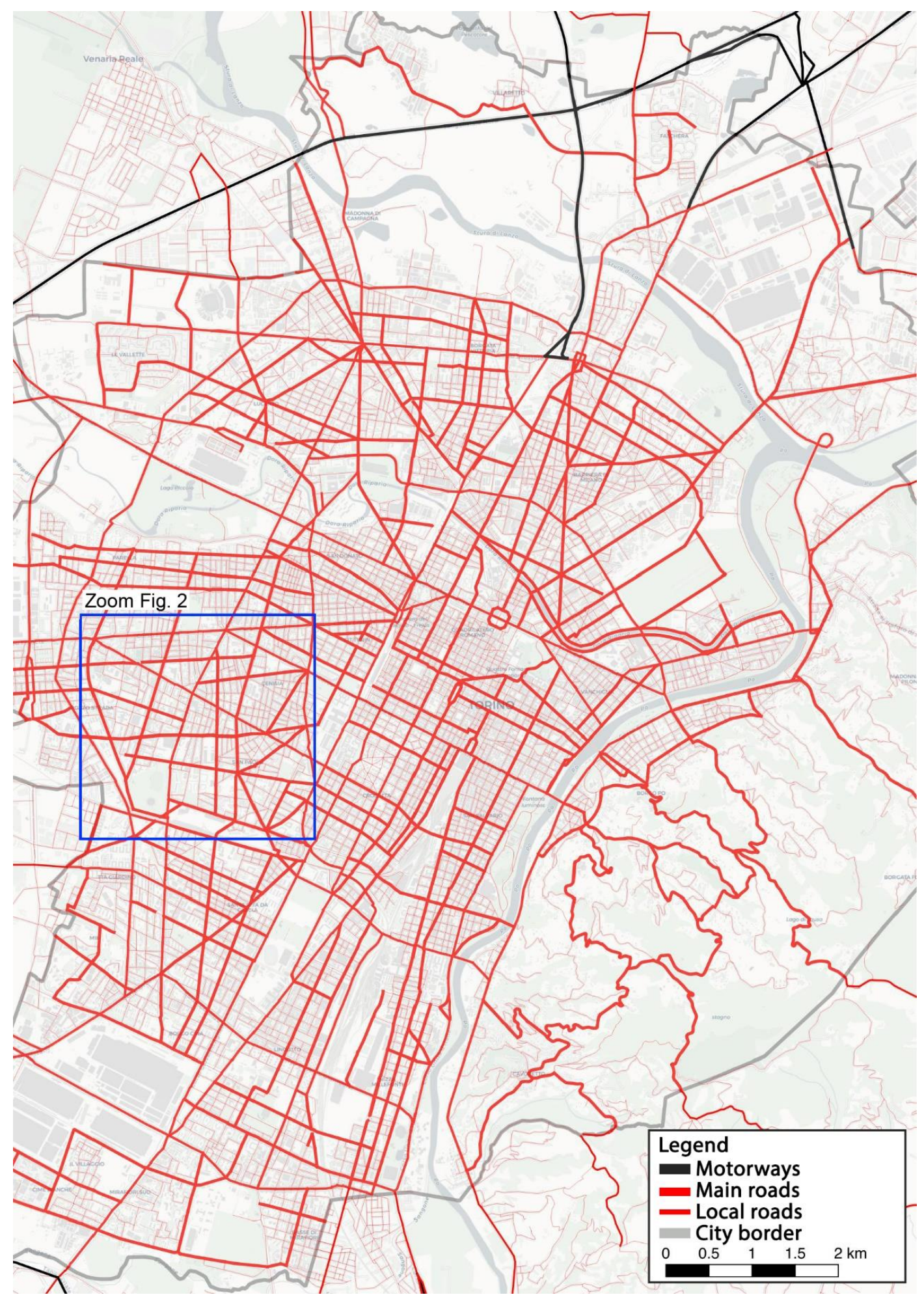

Figure 1. Road hierarchy in Vision 1. 


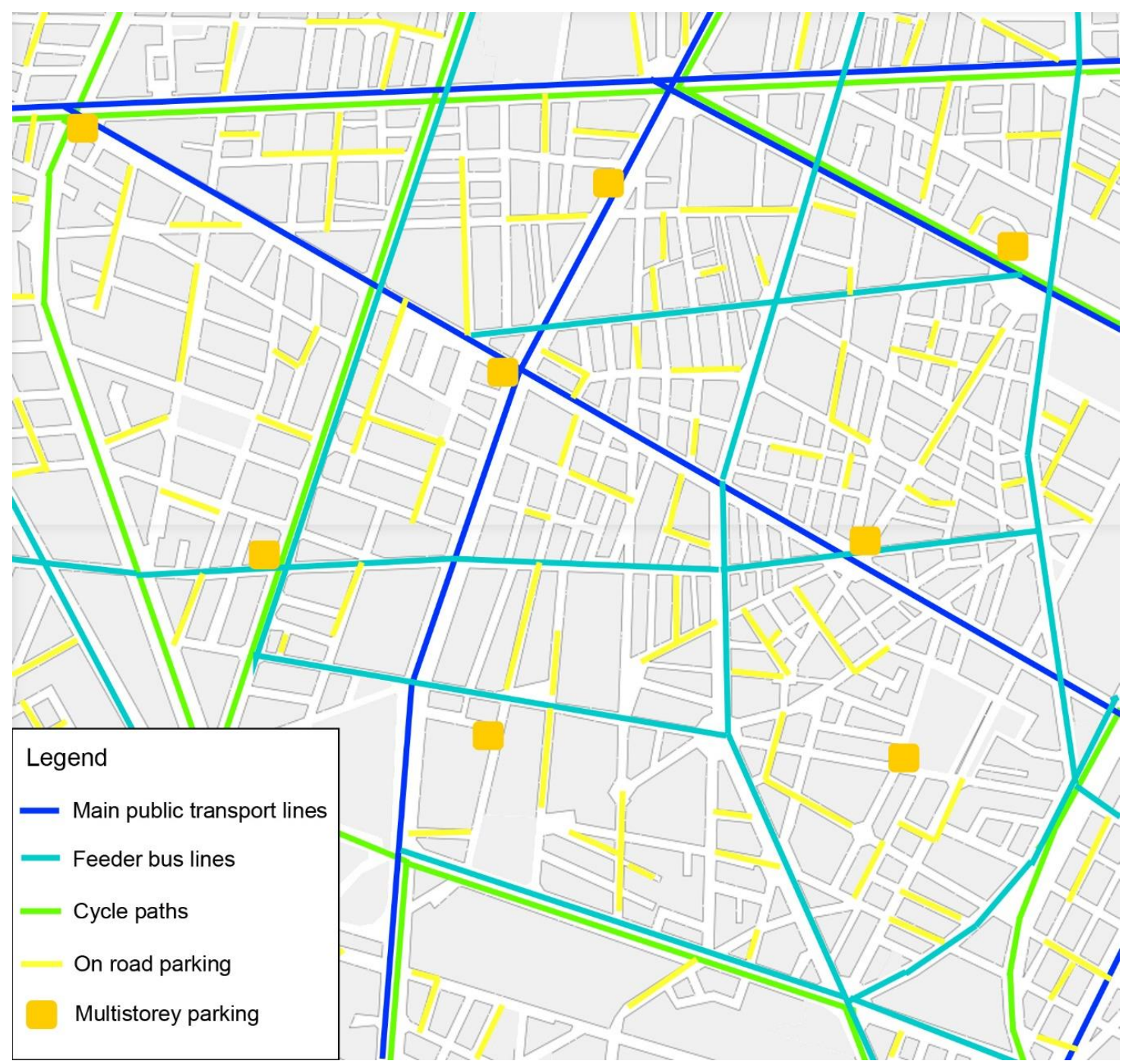

Figure 2. Public transport, cycling, and parking in Vision 1 (zoomed-in view of Figure 1).

Whereas Vision 1 is the outcome of a "moderate" regulatory approach, quite similar to the one currently adopted by the city of Turin, Visions 2 and 3 are the expressions of two more radical and opposite approaches.

Vision 2, called "Strong deregulation", is based on a widespread liberalization and complete confidence in the positive outcomes of technological development; it assumes that AVs would improve road safety, solve congestion problems, and reduce levels of air and noise pollution. In this vision, no speed limit would be set; AVs would be able to circulate everywhere in the road network (Figure 3), with the exception of few pedestrian areas. Parking would only be possible in ad hoc multilevel facilities, evenly distributed in some buildings along the road network (Figure 4), and in intermodal parking facilities located at the terminals of public transport lines. On-road parking would be completely absent and the freed-up space would be dedicated to AV circulation and ad hoc platforms to facilitate the pick-up and drop-off of AVs' passengers. With regards to public transport, only the metropolitan railway service and the metro line 1 would remain operational; all surface public transport would be dismantled (as they are not considered to be competing with AVs), freeing up additional space for $\mathrm{AV}$ circulation. A consistent fleet of shared car would be available, both peer-to-peer and operated by private companies. Pedestrian areas would only be maintained in stately squares and streets of the city's historic center; they would be eliminated in the rest of the city. No new cycle path would be provided, and the existing ones would be removed, increasing the space for AV circulation. As a result, 
Vision 2 assumes that the modal split would show a sharp increase in private motorized transport and a slight increase in car sharing, while the use of both public transport and soft modes would decrease.

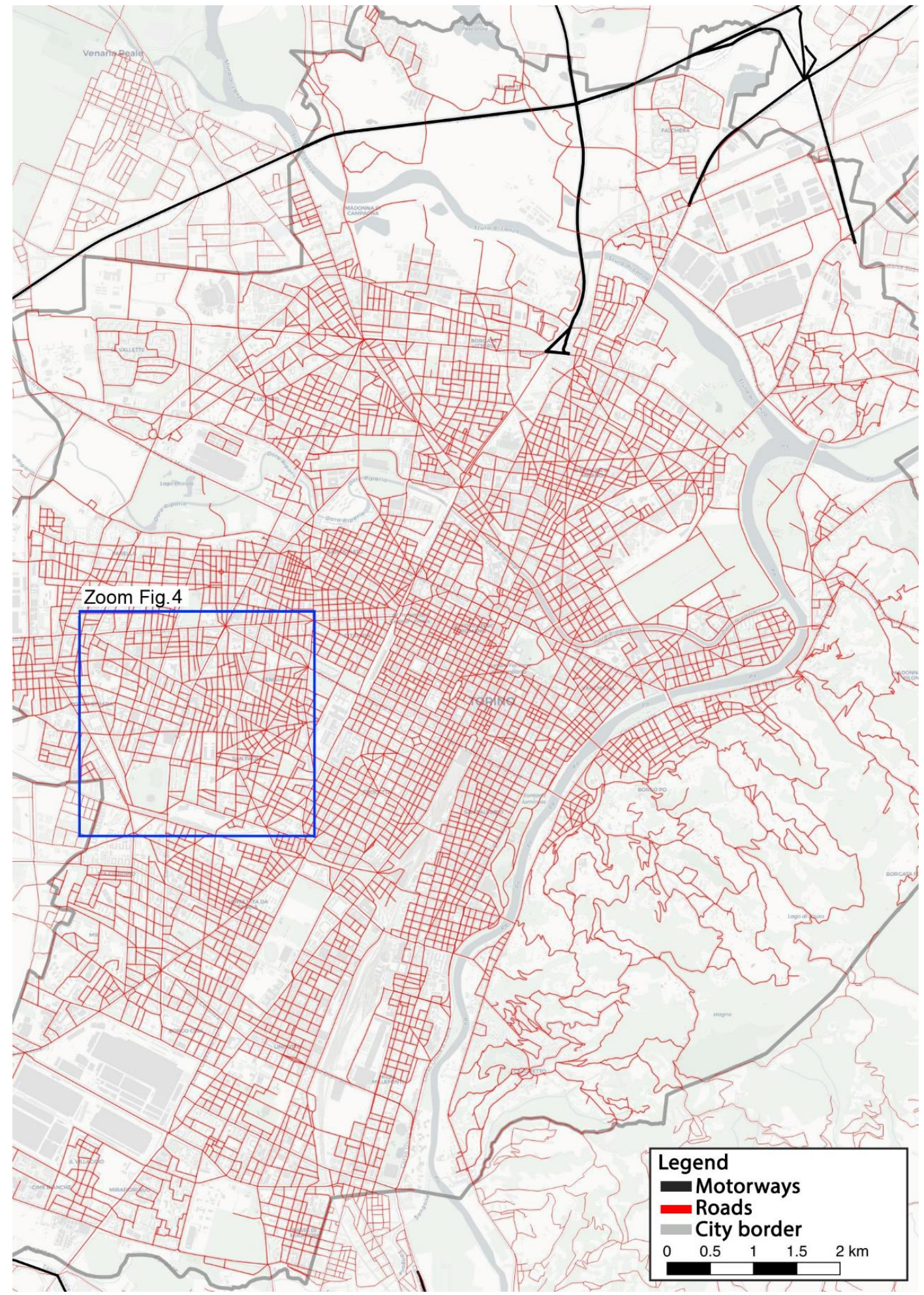

Figure 3. Road hierarchy in Vision 2. 


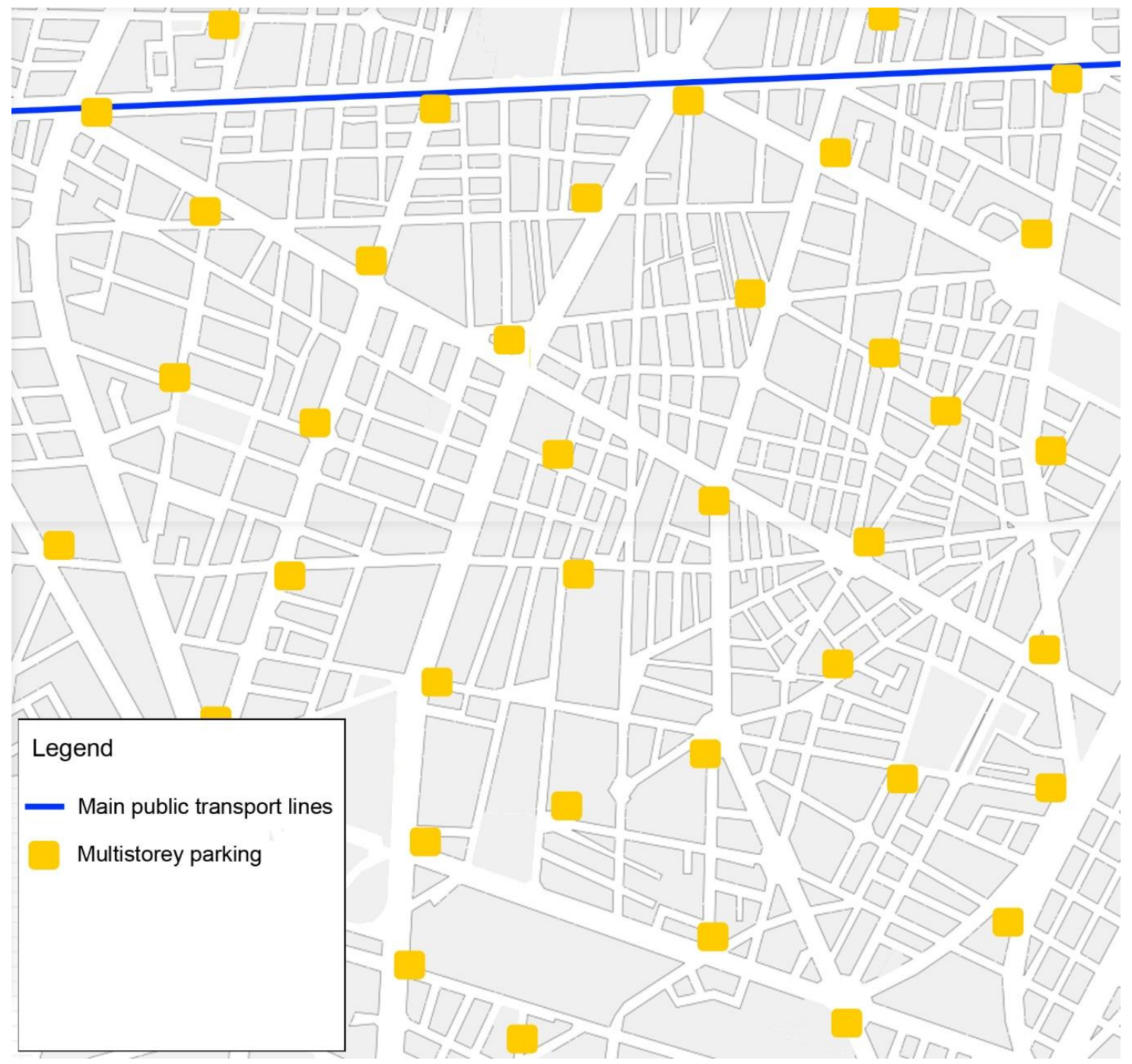

Figure 4. Public transport and parking in Vision 2 (zoomed-in view of Figure 3).

Vision 3, called "Strong regulation", is characterised by a robust regulatory approach. Whereas in Vision 2 AVs are allowed to circulate freely on the entire road network without speed limits, in Vision 3 their circulation is strictly regulated. In this vision, the road network would be hierarchized into main roads (with a speed limit of $50 \mathrm{~km} / \mathrm{h}$ ) and local roads, whose speed limit would not exceed $20 \mathrm{~km} / \mathrm{h}$. The meshes of the main road network would constitute sort of "home zones"; inside each of these zones, every road would be classified as local and only shared AVs or AVs belonging to the residents of the zone would be allowed to circulate (Figure 5). Road parking would be completely removed and the freed-up space would be devoted to non-motorized transport and ad hoc platforms to facilitate boarding and alighting for AVs' passengers; multilevel parking facilities would be built around each home zone, both for residents and visitors (Figure 6), and intermodal parking facilities would be provided at the terminals of public transport lines. As far as public transport is concerned, streetcars would run on reserved lanes on all main roads; transport systems with exclusive right of way (metro and metropolitan railway) would be provided at a higher frequency than that at present, while current bus services would be banned within the home zones (except in the larger ones, where they will be replaced by autonomous shuttles). Car and bike sharing services would be widely provided both on a peer-to-peer basis and by private companies, mainly to the detriment of privately-owned AVs. Shared spaces with walking priority would be systematically extended within all home zones. Cycle lanes will be realized on all main roads and bikers would be allowed to freely ride on local 
roads inside home zones. As a likely outcome of the strict regulation underlying this Vision 3, the modal split would result in a significant increase in all alternative modes to private AVs, the latter being strongly hindered; on the contrary, the use of car sharing services would be boosted. The share of public transport and bikes would slightly increase, and walking would grow more substantially due to the shared spaces in the home zones.

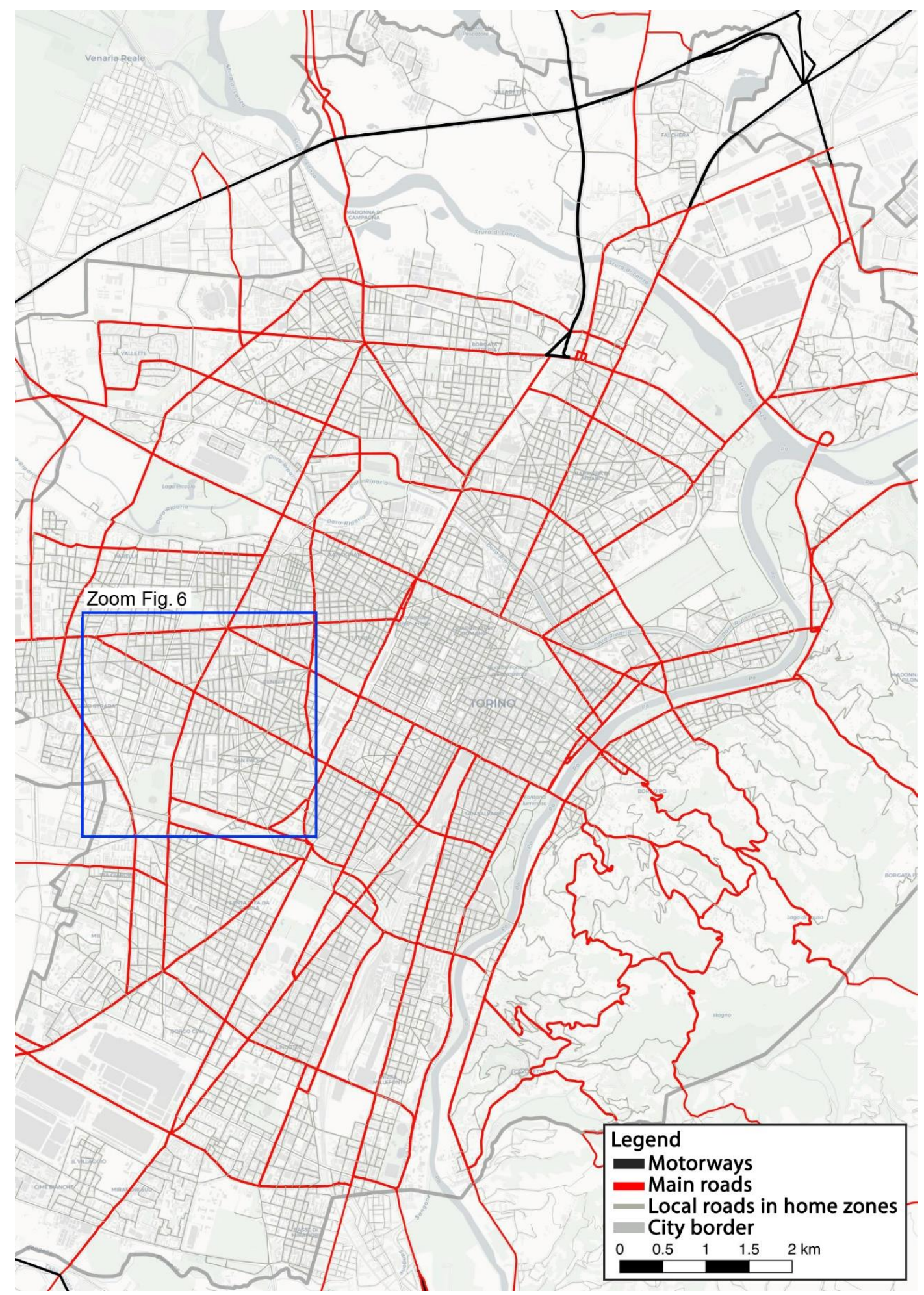

Figure 5. Road hierarchy in Vision 3. 


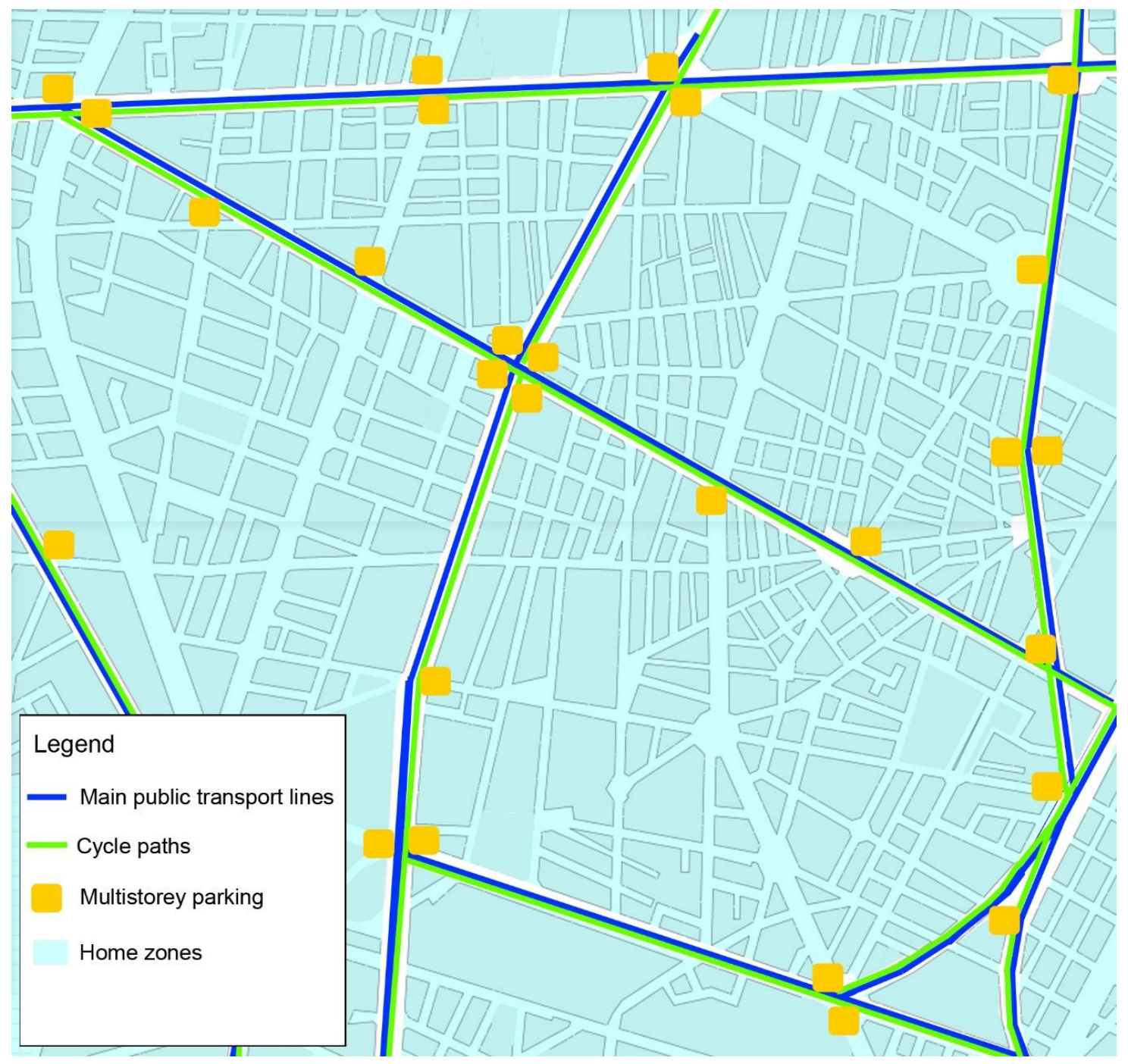

Figure 6. Public transport, cycling, and parking in Vision 3 (zoomed-in view of Figure 5).

\section{Results}

This section illustrates the results of the visioning exercise, first presenting the validation and evaluation of the three visions (5.1) and then some consequent key issues for policies (5.2).

\subsection{Validation and Evaluation of the Three Visions}

The focus group participants were asked to evaluate the three visions proposed by the research team. Overall, the three visions were validated, as the participants did not propose significant changes for any of them. One participant suggested a fourth alternative vision, in which only public transport could circulate in the urban area, private AVs being used only for extra-urban journeys; nevertheless, this vision was not considered significant by the other participants.

The advisability of the three visions was then evaluated through the questionnaire submitted to the 51 interviewees. The advisability of each vision was assessed by calculating the arithmetic mean of the scores (on a 1-10 scale; see Section 4.1) assigned by the 51 respondents to each of its items (Table 3). Vision 3 was clearly considered to be the most advisable-it averaged 7.9 out of 10 , and recorded the highest values for 13 out of 14 items (except main public transport lines). Vision 1 ranked second, with an average score of 6.3; this ranking recurred for most of the 14 items, but for on-road and multi-story parking, this vision was considered the worst. Finally, Vision 2 was deemed the least advisable, with 
a low score, both in terms of the overall average (4.4) and specifically for the items related to public transport and non-motorized mobility.

Table 3. Mean values of advisability of the three visions and the corresponding standard deviations.

\begin{tabular}{|c|c|c|c|c|c|c|}
\hline \multirow{2}{*}{ Item } & \multicolumn{2}{|c|}{ Vision 1} & \multicolumn{2}{|c|}{ Vision 2} & \multicolumn{2}{|c|}{ Vision 3} \\
\hline & Mean & SD & Mean & SD & Mean & SD \\
\hline $\begin{array}{l}1.1 \text { Road hierarchy: Main } \\
\text { roads }\end{array}$ & 5.2 & 2.6 & 4.0 & 2.8 & 7.7 & 2.4 \\
\hline $\begin{array}{l}1.2 \text { Road hierarchy: Local } \\
\text { roads }\end{array}$ & 5.0 & 2.6 & 3.7 & 2.7 & 7.8 & 2.4 \\
\hline $\begin{array}{l}\text { 2.1 Limitation to vehicle } \\
\text { circulation }\end{array}$ & 5.9 & 2.6 & 3.8 & 3.2 & 7.4 & 2.6 \\
\hline 3.1 On-road parking & 6.4 & 2.4 & 6.5 & 2.5 & 7.9 & 1.9 \\
\hline 3.2 Multi-story parking & 6.0 & 2.4 & 6.6 & 2.3 & 8.2 & 1.7 \\
\hline 3.3 Intermodal parking & 6.2 & 2.4 & 6.1 & 2.4 & 8.1 & 1.5 \\
\hline 4.1 Main PT lines & 7.2 & 2.3 & 3.9 & 2.4 & 7.1 & 2.8 \\
\hline 4.2 Feeder PT lines & 6.3 & 2.4 & 3.6 & 2.5 & 7.5 & 2.4 \\
\hline 4.3 Lanes reserved to PT & 6.8 & 2.4 & 3.3 & 2.7 & 7.9 & 2.1 \\
\hline 5.1 Motorized sharing & 6.5 & 2.2 & 6.0 & 2.2 & 7.8 & 2.3 \\
\hline 5.2 Non-motorized sharing & 6.6 & 2.0 & 3.7 & 2.4 & 8.4 & 1.9 \\
\hline 6. Pedestrian areas & 7.4 & 1.8 & 3.8 & 2.4 & 7.9 & 2.4 \\
\hline 7. Cycling facilities & 6.8 & 1.9 & 2.4 & 2.0 & 8.2 & 2.3 \\
\hline 8. Modal share & 5.6 & 2.1 & 3.3 & 2.5 & 8.5 & 1.7 \\
\hline
\end{tabular}

Vision 3 also showed the least dispersed distribution of the scores, as its standard deviation was the lowest of the three visions for ten out of 14 items, while dispersion was high for the issues concerning the main public transport lines, motorized sharing, cycling, and pedestrian mobility.

It is interesting to note that Vision 3 was considered the most advisable by 45 of the 51 interviewees; only one respondent preferred Vision 2, and five preferred Vision 1. This meant that Vision 3 was also seen as the most sustainable by stakeholders belonging to the automotive sector, who could have been expected to prefer Vision 2, which is more conducive to a wide diffusion and use of AVs.

\subsection{Key Issues for Policies}

As the interviewees were almost unanimous on the need for strict regulation of AVs, it is essential to understand what to regulate and how to do it. In this sense, the elaboration of the three visions and their discussion in the focus group and in the interviews brought out some key issues that are crucial for short- and medium-term policy making.

\subsubsection{Circulation}

A first issue concerns how private AVs are allowed to circulate in the road network. Should they be free to travel on the whole road network, as in Vision 2? Or should their circulation be permitted on only part of the network (e.g., the main roads which are primarily devoted to mediumand long-distance intra-urban trips), and discouraged in the rest of the network? This second solution was preferred by most interviewees, who rated Vision 3 as the most sustainable. In this vision, access of privately owned AVs to the secondary roads inside home zones is completely restricted (except the zone where the owner of the $\mathrm{AV}$ resides); $\mathrm{AVs}$ can reach the boundary of the area where the trip destination is located, but the last link in the travel chain has to be made on foot, by a shared bike, etc. The reason for this preference was highlighted in the focus group and in the interviews-electric AVs will have less impact on the livability of residential areas in terms of air pollution, noise, and safety than traditional cars; however, their spatial footprint is likely to remain the same, and their circulation will continue to negatively interfere with the social use of secondary roads. In Vision 3, this interference is limited, as cut-through traffic in home zones is prevented and consequently the number 
of circulating AVs is reduced inside the home zone, to the benefit of their livability. Some European cities are already adopting regulations to discourage cut-through traffic in home zones, thanks to speed limits, changes in traffic directions, shared spaces, etc., such as Grenoble and Paris in France [55-57], or Barcelona in Spain $[58,59]$. In Turin, restrictions to car circulation have so far been implemented almost exclusively in the central historical area, so a completely new approach would be needed.

These measures could also be used to promote a transition from ownership to sharing, which is deemed a key factor in reducing potential negative impacts of AV [60,61]. This is another element of Vision 3 that was valued by the interviewees-this vision, in fact, applies restrictions to circulation only to private AVs and not to shared AVs, which are free to enter secondary roads. This also offers a solution to one of the major potential critical issues of Vision 3, namely the impossibility of reaching one's final destination using one's own AV; this impossibility could be a problem for elderly people, pregnant women, etc., but can be overcome by the use of a shared AV. As highlighted in the focus group, Vision 3 could also favor community car sharing services, organized at the home zone level.

\subsubsection{Parking}

One of the potential impacts of AVs on the city, often mentioned in literature, is the reduction of parking demand. This reduction would affect the amount of parking (if AVs are mostly shared) and, in particular, the number of roadside parking spaces. As a matter of fact, AVs would be able to drop-off the passengers at their destination and then travel empty to reach the nearest vacant parking space. In this sense, Vision 2 and 3 can contribute to the livability of urban neighborhoods, as space on roads can be freed up by gathering parking in dedicated facilities (multilevel parking). But this raises the question of where to locate these facilities. What is the maximum distance that AVs should be allowed to travel empty to reach a parking? In the literature it is generally proposed to concentrate parking for AVs outside the central urban area, in low-density outskirts just for creating new development opportunities in the center [62]; but in the (generally) dense European cities, this approach would imply long, empty trips to reach the external parking [34]. On the contrary, both Visions 2 and 3 are aimed to reduce these empty trips by distributing multilevel parking facilities over the whole road network (Vision 2) or just over the main network around the home zones (Vision 3). In particular, Vision 3 was preferred by the interviewees, as private AVs would not generate traffic inside the home zones while reaching the nearest parking; but a warning was raised about the risk of congestion on the main roads in the vicinity of these parking facilities.

It is important to underline that these strategies already require policy measures in the short and medium term, especially in European cities such as Turin, where vacant lots in dense central urban areas are generally rare. Should current vacant lots be used for new residential or tertiary buildings, or rather for multilevel parking so as to begin the process of reducing parking on road? Moreover, the sustainability of this spatial strategy was questioned by the interviewees in economic terms, as prices of vacant lots in central areas can be very high.

Finally, if parking on road is removed, areas for picking-up/dropping-off passengers would probably be necessary, and the number of lots to be allotted for a block and choosing a location for them would be some of crucial issues for urban planning and design.

\subsubsection{Multimodality}

A key issue about $\mathrm{AVs}$ is how to prevent them from increasing their modal share at the expense of non-motorized mobility (and its health benefits), not least because they would make even short trips on foot from origin to parking, and from parking to destination, unnecessary. At the same time, as highlighted in the previous sections, AVs would probably allow the reduction of car parks on road; this freed up space could be dedicated to pedestrians and cyclists. The interviewees justified their preference for Vision 3 manly because it combined these two issues-it forbids privately owned AVs from entering home zones, thus, allowing all local roads to be re-designed as shared space (without 
parking) with priority for pedestrians and cyclists; this would also force the drivers to walk or bike to their final destination.

With regard to public transport, the diffusion of AVs questions its spatial organization. Will a hierarchical structure, based on a main underground and streetcar lines and secondary feeder bus, still work? Or could feeder buses be replaced by shared AVs, robot-cabs, and so on? As emphasized in the focus group, this perspective is particularly relevant for a city like Turin, which, due to financial constraints, is now restructuring its public transport supply, and is deciding whether to linearly cut the frequencies of all lines or to boost the main lines to the detriment of secondary feeder buses. Even for Turin, Vision 2 (which would relieve the city of the need to provide most of the current public transport supply) was considered less advisable than Vision 3; a good quality transport system was in fact considered by the interviewees indispensable to concentrate the circulation of private AVs only on the main road and avoid cut-through traffic in home zones.

\section{Concluding Remarks}

As Stead and Vaddadi recently stated [24], "ultimately, the future role of AVs in influencing urban form and structure is not so much dependent on the technology and level of automation of vehicles but rather on the regulation of this technology and the governance of cities and regions".

The elaboration and discussion of the three visions for the city of Turin has confirmed that regulation of $\mathrm{AV}$ circulation and parking is likely to play an important role in governing the impacts of this innovation on the city. This article focused on a single case-study, therefore, any claim to exhaustiveness must be excluded. However, most of the issues that emerged are not specific to Turin, but could be relevant for planning the AV transition in general.

First, the elaboration of $\mathrm{AV}$ visions for a specific city invites planners and researchers to take into consideration the real spatial and infrastructural structure of the city, and how to tailor the regulation of $\mathrm{AV}$ circulation and parking in the different parts of this structure. In this way, visioning exercises reveal how challenging it is to rethink traditional transport and urban items (such as road hierarchy, speed limits, traffic restrictions, parking location, multimodality, shared spaces, etc., in their mutual relationships) for $\mathrm{AVs}$, much more than acontextual theoretical speculations (which are so far dominant in the literature) often do.

Second, it is important not to approach the regulation of AV circulation and parking as a sectorial problem, but to frame it with regards to the key values assumed for city development. In the case of Turin, the focus on urban (economic, social, and environmental) sustainability let emerge the livability of residential neighborhood as a fundamental issue in the preference of Vision 3 by the stakeholders. As also suggested by González-González et al. [15], each city should explicitly state the core values of its urban agenda in visioning how to integrate AVs into the context.

Third, visions such as the ones presented in this article could be used in backcasting exercises to identify which measures could be adopted in the short- and medium-term, to guide AV transition towards the desired direction. This could be particularly important for cities (such as Turin) that are elaborate their SUMP; indeed, SUMPs generally cover a time horizon of at least ten years, during which a first transition to AVs could accelerate. In the case of Turin, the vision preferred by the local stakeholder is very different from the current state of the mobility system, and a significant planning effort would be necessary to achieve that vision, even in a thirty-year horizon. In this context, the authors of this article are carrying out a complete backcasting exercise involving Turin stakeholders, in order to identify which measures are needed to direct the evolution of the city towards Vision 3, and when to implement them in the next thirty years. 
It is interesting to note that most of the regulation actions proposed in Vision 3 could be considered "no regret" measures, both for Turin and for other cities in similar conditions. Indeed, these measures could be undertaken in the short- or medium-term (when fully autonomous vehicles would still be very few, or none) to reduce the negative impacts of current human-driven cars on the city (noise, air pollution, accidents, etc.). On a longer time-horizon, electric, fully autonomous vehicles are likely to minimize most of these impacts, but the same measures could turn out to be useful to address other expected negative effects of AVs, such as excessive reduction of active mobility, conflicts with pedestrians and cyclists, and increase in vehicle mileage.

From a methodological point of view, combining the think-tank model and the participatory model in the visioning process turned out to be an appropriate and convenient approach, both for the elaboration of the visions and the selection of the most advisable one. In particular, the wide convergence of most interviewees (even those from the automotive sector) on Vision 3 was remarkable, as this could then be used as the normative target to pursue in the backcasting process. At the same time, the difficulty to involve private common citizens (individually or in associate forms) in this process in a way that could be representatively significant must be pointed out.

Another methodological issue concerns the spatial scale of the visions, which were limited to the city level in this study. In fact, so far in Italy, regulation of circulation and parking is a responsibility of the Municipalities. At the same time, at this scale it is not possible to intercept the potential impacts of AVs on the sprawling processes. Wider visions, typically on a metropolitan scale, would be needed. Most of the participants in the focus group and many interviewees stressed the importance of integrating regulatory measures, which could be adopted in the city of Turin, with measures to prevent sprawl, which should be implemented together with the surrounding Municipalities.

Moreover, the evaluation of the three visions was based on the assessment by local stakeholders in the interviews. It would be interesting to use transport quantitative models to simulate the effects of the proposed regulation of AV circulation and parking on modal split, as well as to simulate the impacts on land use and urban growth patterns through land use-transport interaction models (LUTI).

Finally, in the three proposed visions, only the measures aimed at regulating how and where AVs and other means of transport could circulate and park in the city were taken into consideration. Other kinds of transport policies could be integrated into the visions. For example, pricing measures, such as congestion charging, road pricing, and parking tariffs, which could be spatially differentiated to regulate the circulation and parking of AVs.

Author Contributions: Conceptualization, L.S., V.R., J.S., and E.V.B.; Formal analysis, J.S.; Investigation, L.S., V.R., J.S., and E.V.B.; Methodology, L.S., V.R., J.S., and E.V.B.; Supervision, L.S.; Writing—original draft, L.S., V.R., J.S., and E.V.B.; Writing—review \& editing, V.R., J.S., and E.V.B.

Funding: This research received no external funding.

Conflicts of Interest: The authors declare no conflict of interest.

\section{References}

1. Docherty, I.; Marsden, G.; Anable, J. The governance of smart mobility. Transport. Res. Part A Policy Pract. 2018, 115, 114-125. [CrossRef]

2. Hopkins, D.; Schwanen, T. Automated Mobility Transitions: Governing Processes in the UK. Sustainability 2018, 10, 956. [CrossRef]

3. Marchau, V.; Zmud, J.; Kalra, N. Editorial for the special issue-Autonomous vehicle policy. Transp. Res. Part A Policy Pract. 2018, 122, 120-124. [CrossRef]

4. Zakharenko, R. Self-driving cars will change cities. Reg. Sci. Urban Econ. 2016, 61, 26-37. [CrossRef]

5. Linden, A.; Fenn, J. Understanding Gartner's Hype Cycles; Gartner Inc.: Stamford, CT, USA, 2003.

6. Walker, M. Hype Cycle for Emerging Technologies; Gartner Inc.: Stamford, CT, USA, 2018.

7. Cohen, T.; Cavoli, C. Automated vehicles: Exploring possible consequences of government (non)intervention for congestion and accessibility. Transp. Rev. 2018, 39, 129-151. [CrossRef] 
8. Faisal, A.; Yigitcanlar, T.; Kamruzzaman, M.; Currie, G. Understanding autonomous vehicles: A systematic literature review on capability, impact, planning and policy. J. Transp. Land Use 2019, 12, 45-72. [CrossRef]

9. Fraedrich, E.; Heinrichs, D.; Bahamonde-Birke, F.J.; Cyganski, R. Autonomous driving, the built environment and policy implications. Transp. Res. Part A Policy Pract. 2018, 122, 162-172. [CrossRef]

10. Soteropoulos, A.; Berger, M.; Ciari, F. Impacts of automated vehicles on travel behaviour and land use: An international review of modelling studies. Transp. Rev. 2019, 39, 29-49. [CrossRef]

11. Guerra, E. Planning for Cars That Drive Themselves: Metropolitan Planning Organizations, Regional Transportation Plans, and Autonomous Vehicles. J. Plan. Educ. Res. 2016, 36, 210-224. [CrossRef]

12. Legacy, C.; Ashmore, D.; Scheurer, J.; Stone, J.; Curtis, C. Planning the driverless city. Transp. Rev. 2019, 39, 84-102. [CrossRef]

13. Milakis, D. Long-term implications of automated vehicles: An introduction. Transp. Rev. 2018, 39, 1-8. [CrossRef]

14. Banister, D.; Hickman, R. Transport futures: Thinking the unthinkable. Transp. Policy 2013, 29, $283-293$. [CrossRef]

15. González-González, E.; Nogués, S.; Stead, D. Automated vehicles and the city of tomorrow: A backcasting approach. Cities 2019, 94, 153-160. [CrossRef]

16. Tuominen, A.; Tapio, P.; Varho, V.; Järvi, T.; Banister, D. Pluralistic backcasting: Integrating multiple visions with policy packages for transport climate policy. Futures 2014, 60, 41-58. [CrossRef]

17. Vergragt, P.J.; Quist, J. Backcasting for sustainability: Introduction to the special issue. Technol. Forecast. Soc. Chang. 2011, 78, 747-755. [CrossRef]

18. Fagnant, D.J.; Kockelman, K.M. The travel and environmental implications of shared autonomous vehicles, using agent-based model scenarios. Transp. Res. Part C Emerg. Technol. 2014, 40, 1-13. [CrossRef]

19. Fraedrich, E.; Beiker, S.; Lenz, B. Transition pathways to fully automated driving and its implications for the sociotechnical system of automobility. Eur. J. Futures Res. 2015, 3, 11. [CrossRef]

20. Gruel, W.; Stanford, J.M. Assessing the Long-term Effects of Autonomous Vehicles: A Speculative Approach. Transp. Res. Procedia 2016, 13, 18-29. [CrossRef]

21. Milakis, D.; Snelder, M.; van Arem, B.; van Wee, G.P.; Homem de Almeida Correia, G. Development and transport implications of automated vehicles in the Netherlands: Scenarios for 2030 and 2050. Eur. J. Transp. Infrastruct. Res. 2017, 17. [CrossRef]

22. Papa, E.; Ferreira, A. Sustainable Accessibility and the Implementation of Automated Vehicles: Identifying Critical Decisions. Urban Sci. 2018, 2, 5. [CrossRef]

23. Smolnicki, P.M.; Sołtys, J. Driverless Mobility: The Impact on Metropolitan Spatial Structures. Procedia Eng. 2016, 161, 2184-2190. [CrossRef]

24. Stead, D.; Vaddadi, B. Automated vehicles and how they may affect urban form: A review of recent scenario studies. Cities 2019, 92, 125-133. [CrossRef]

25. Thakur, P.; Kinghorn, R.; Grace, R. Urban form and function in the autonomous era. In Proceedings of the Australasian Transport Research Forum 2016, Melbourne, Australia, 16-18 November 2016; p. 15.

26. Marletto, G. Who will drive the transition to self-driving? A socio-technical analysis of the future impact of automated vehicles. Technol. Forecast. Soc. Chang. 2019, 139, 221-234. [CrossRef]

27. Cavoli, C.; Phillips, B.; Cohen, T.; Jones, P. Social and behavioural questions associated with Automated Vehicles: A Literature Review; Department for transport: London, UK, 2017.

28. Yigitcanlar, T.; Wilson, M.; Kamruzzaman, M. Disruptive Impacts of Automated Driving Systems on the Built Environment and Land Use: An Urban Planner's Perspective. J. Open Innov. Technol. Mark. Complex. 2019, 5, 24. [CrossRef]

29. Litman, T. Autonomous Vehicle Implementation Predictions Implications for Transport Planning; Victoria Transport Policy Institute: Victoria, BC, Canada, 2019; p. 39.

30. Metz, D. Developing Policy for Urban Autonomous Vehicles: Impact on Congestion. Urban Sci. 2018, 2, 33. [CrossRef]

31. Zhang, W.; Guhathakurta, S.; Fang, J.; Zhang, G. Exploring the impact of shared autonomous vehicles on urban parking demand: An agent-based simulation approach. Sustain. Cities Soc. 2015, 19, 34-45. [CrossRef]

32. Childress, S.; Nichols, B.; Charlton, B.; Coe, S. Using an Activity-Based Model to Explore the Potential Impacts of Automated Vehicles. Transp. Res. Rec. 2015, 2493, 99-106. [CrossRef] 
33. Fagnant, D.J.; Kockelman, K. Preparing a nation for autonomous vehicles: Opportunities, barriers and policy recommendations. Transp. Res. Part A Policy Pract. 2015, 77, 167-181. [CrossRef]

34. Gavanas, N. Autonomous Road Vehicles: Challenges for Urban Planning in European Cities. Urban Sci. 2019, 3, 61. [CrossRef]

35. Meyer, J.; Becker, H.; Bösch, P.M.; Axhausen, K.W. Autonomous vehicles: The next jump in accessibilities? Res. Transp. Econ. 2017, 62, 80-91. [CrossRef]

36. Zhang, W.; Guhathakurta, S. Residential Location Choice in the Era of Shared Autonomous Vehicles. J. Plan. Educ. Res. 2018. [CrossRef]

37. Milakis, D.; Kroesen, M.; van Wee, B. Implications of automated vehicles for accessibility and location choices: Evidence from an expert-based experiment. J. Transp. Geogr. 2018, 68, 142-148. [CrossRef]

38. Botello, B.; Buehler, R.; Hankey, S.; Mondschein, A.; Jiang, Z. Planning for walking and cycling in an autonomous-vehicle future. Transp. Res. Interdiscip. Perspect. 2019, 1, 100012. [CrossRef]

39. Parkin, J.; Clark, B.; Clayton, W.; Ricci, M.; Parkhurst, G. Autonomous vehicle interactions in the urban street environment: A research agenda. Proc. Inst. Civ. Eng. Munic. Eng. 2017, 171, 15-25. [CrossRef]

40. Millard-Ball, A. Pedestrians, Autonomous Vehicles, and Cities. J. Plan. Educ. Res. 2018, 38, 6-12. [CrossRef]

41. Alessandrini, A.; Campagna, A.; Site, P.D.; Filippi, F.; Persia, L. Automated Vehicles and the Rethinking of Mobility and Cities. Transp. Res. Procedia 2015, 5, 145-160. [CrossRef]

42. Jones, E.C.; Leibowicz, B.D. Contributions of shared autonomous vehicles to climate change mitigation. Transp. Res. Part D Transp. Environ. 2019, 72, 279-298. [CrossRef]

43. International Transport Forum. Urban Mobility System Upgrade; OECD: Paris, France, 2015.

44. Li, S.; Sui, P.-C.; Xiao, J.; Chahine, R. Policy formulation for highly automated vehicles: Emerging importance, research frontiers and insights. Transp. Res. Part A Policy Pract. 2018, 124, 573-586. [CrossRef]

45. Stone, J.; Ashmore, D.; Scheurer, J.; Legacy, C.; Curtis, C. Planning for Disruptive Transport Technologies: How Prepared Are Australian Transport Agencies? In Governance of the Smart Mobility Transition; Emerald Publishing Limited: Bingley, UK, 2018; pp. 123-136.

46. Guerra, E.; Morris, E.A. Cities, Automation, and the Self-parking Elephant in the Room. Plan. Theory Pract. 2018, 19, 291-297. [CrossRef]

47. Healey, P. Making Better Places: The Planning Project in the Twenty-First Century; Macmillan International Higher Education: Basingstoke, Hampshire, 2010; ISBN 978-1-137-01379-8.

48. Lyons, G.; Davidson, C. Guidance for transport planning and policymaking in the face of an uncertain future. Transp. Res. Part A Policy Pract. 2016, 88, 104-116. [CrossRef]

49. Walker, W.E.; Marchau, V.A.W.J.; Swanson, D. Addressing deep uncertainty using adaptive policies: Introduction to section 2. Technol. Forecast. Soc. Chang. 2010, 77, 917. [CrossRef]

50. Soria-Lara, J.A.; Banister, D. Participatory visioning in transport backcasting studies: Methodological lessons from Andalusia (Spain). J. Transp. Geogr. 2017, 58, 113-126. [CrossRef]

51. Börjeson, L.; Höjer, M.; Dreborg, K.H.; Ekvall, T.; Finnveden, G. Scenario types and techniques: Towards a user's guide. Futures 2006, 38, 723-739. [CrossRef]

52. Carlsson-Kanyama, A.; Dreborg, K.H.; Moll, H.C.; Padovan, D. Participative backcasting: A tool for involving stakeholders in local sustainability planning. Futures 2008, 40, 34-46. [CrossRef]

53. Dreborg, K.H. Scenarios and Structural Uncertainty; Royal Institute of Technology: Stockholm, Sweden, 2004.

54. Wilkinson, S. Focus group methodology: A review. Int. J. Soc. Res. Meth. 1998, 1, 181-203. [CrossRef]

55. Godillon, S. Conflits autour de la «pacification» du trafic automobile. Analyse des politiques de modération de la vitesse à Paris. L'Espace Politique Revue en ligne de géographie politique et de géopolitique 2016, 30.

56. Ville de Grenoble Ville apaisée: Grenoble à 30 km/h Depuis le 1er Janvier 2016. Available online: https://www. grenoble.fr/actualite/75/103-ville-apaisee-grenoble-a-30-km-h-depuis-le-1er-janvier-2016.htm (accessed on 6 August 2019).

57. Ville de Paris Zones 30: Comment Ça Marche? Available online: https://www.paris.fr/actualites/zones-30comment-ca-marche-5507 (accessed on 6 August 2019).

58. Scudellari, J.; Staricco, L.; Vitale Brovarone, E. Implementing the Supermanzana approach in Barcelona. Critical issues at local and urban level. J. Urban Des. 2019, 1-22. [CrossRef]

59. Ajuntament Barcelona Superilles. Available online: http://ajuntament.barcelona.cat/superilles/es (accessed on 6 August 2019). 
60. Fagnant, D.J.; Kockelman, K.M. Dynamic ride-sharing and fleet sizing for a system of shared autonomous vehicles in Austin, Texas. Transportation 2018, 45, 143-158. [CrossRef]

61. Burns, L.D.; Jordan, W.C.; Scarborough, B.A. Transforming Personal Mobility. Earth Inst. 2012, 431, 432.

62. Heinrichs, D. Autonomous Driving and Urban Land Use. In Autonomous Driving: Technical, Legal and Social Aspects; Maurer, M., Gerdes, J.C., Lenz, B., Winner, H., Eds.; Springer: Berlin/Heidelberg, Germany, 2016; pp. 213-231. ISBN 978-3-662-48847-8. [CrossRef]

(c)

(C) 2019 by the authors. Licensee MDPI, Basel, Switzerland. This article is an open access article distributed under the terms and conditions of the Creative Commons Attribution (CC BY) license (http://creativecommons.org/licenses/by/4.0/). 